\title{
Independent Thinking: A Path to Outstanding Scholarship
}

\section{独立思考精神: 优秀学者的必备品质}

\section{Xiao-Ping Chen (陈晓莉)}

\section{摘要}

本文讨论独立思考精神对培养优秀学者的重要性。通过分析在中国文化中保持独立思考精神之 难度, 作者提出培养独立思考精神的四种方法: 认识少数人的力昷; 拥有抗拒压力的覓气：将 外在压力转化成内在动力; 兼听则明 : 以及培养对管理研究的激情。

关键词：独立思考, 少数人的力且, 抗拒压力, 兼听则明, 保持激情 


\section{Which Way through the Open Door? Reflections on the Internationalization of Chinese Firms 如何走出对外开放之门? 关于中国企业国际化的思考}

\section{Max Boisot and Marshall W. Meyer}

摘要

主流的国际化理论认为企业在向国外扩张之前需要首先占领国内市场：换言之，大型的骞头 企业最有可能进行国际化。然而, 对于经济条块分割、企业规模按照全球标准普遍较小的中 国而言, 情况却截然不同。基于跨地区边界 (在中国即省界) 营运和跨国家边界营运的相对 交易成本, 我们建立了一个小企业国际化模型。当跨地区营运的交易成本高于跨国界营运的 成本时，企业在发展早期就会进行国际化。在中国，地方保护主义和低效的基础设施增加了 企业的经营成本：此外，西方的产权保护、国内公司重组为国外公司在国内经营的好处，降 低了中国公司“走出去”的成本。我们用“制度套利”这一术语来描述中国企业利用国际化 来追求有利的经营环境的行为。本文认为, 众多中国企业的国际化行为可能基于从母国的战 略退出, 而非对国外市场的战略进入。

关键词：中国企业, 国际化, 中国经济改革, 套利, 海外经营 


\section{Government-oriented Corporate Public Relation Strategies in Transitional China \\ 中国经济转型时期企业的政府导向公关策略}

\section{Yuanqiong He (贺远琼) and Zhilong Tian (田志龙)}

\section{摘要}

采用内容分析法, 本文分别对76家中国企业、以及6家中国知名企业官方网站上的公关 活动新闻报道进行了探索性研究, 并在此基础上提出了政府导向公关策略的初始和修 正模型。根据资源依赖理论, 本文提出中国企业在管理企业对政府资源的依赖方式和 程度时, 使用了六种公关策略, 包括参观策略、公益策略、参与策略、公关策略、党 建策略和政治宣传策略；中国企业通过四个步骤来实施这些策略，即开展具有经济、 社会和政治重要性的公关活动：获得政府的参与和认可：构建符合政府期望的资源、 伦理和文化合法性：就企业关注的事项与政府互动, 以影响政府政策。最后, 我们发 现不同所有制企业在使用政府导向公共关系策略、以及公关活动所涉及的政府层次和 事项等方面存在差异。

关键词：资源依赖理论, 政府导向公关策略, 内容分析, 制度环境, 网站 


\section{Abusive Supervision and Contextual Performance: The Mediating Role of Emotional Exhaustion and the Moderating Role of Work Unit Structure 苛责式督导与下属的职外表现: 情绪疲忞的中介角色及工作 单位结构的调节作用}

Samuel Aryee, Li-Yun Sun (孙立云), Zhen Xiong George Chen (陈镇雄), and Yaw A. Debrah

摘要

本文探讨了主管苛责式督导对下属职外表现的影响的过程, 重点研究了情绪疲忞的中介角色 及工作单位结构的调节作用。研究数据来自中国东北多家公司的285位下属及其直接主管。 结果显示：（1）情绪疲急在苛责式督导与下属的职外表现的两个维度（人际促进及工作奉 献) 关系间起中介作用：（2）工作单位结构对上述关系起调节作用一当工作单位结构是 “机械式”时，上述关系较强；而当工作单位结构是“有机式”时，上述关系较娽。

关键词：苛责式督导, 情绪疲急, 工作单位结构, 下属的职外表现 


\section{Toward a Geocentric Framework of Trust: An Application to Organization Trust 建立跨文化的信任理论梅架: 在组织信任中的应用}

\section{Peter Ping Li (李平)}

摘要

在信任维度和类型分类的基础上, 本文提出两种新的分类方法, 即信任的形式和来源。这 四个分类方法构成了一个有关信任, 特别是组织信任的理论整合框架。基于形式分类, 信 任由建立的内容和过程两个维度构成。其中, 信任建立的内容强调信任关系的强弱, 信任 廷立的过程则强调信任关系的成熟程度。基于来源的分类, 信任由是否来自人际关系和信 任立生的层级两方面构成。其中, 人际关系维度讨论了信任是否具有人际关系基础, 而信 任产生的层级讨论了信任维系在两人之间或是群体之间。以信任建立的手段、领导作用以 及信任选择行为为基础, 我们可将信任的四个分类方法进行整合, 形成一个超越东西方文 化的理论枉架。此框架对于整合交易成本和交易价值这对矛盾体, 解释企业联盟, 具有特 殊的理论意义。

关键词：组织信任, 信任建立, 领导, 交易价值, 跨文化理论框架, 矛盾视角 